\title{
La crítica periodística en el teatro peruano
}

\section{Sara Joffré}

\section{RESUMEN}

Este ensayo destaca la figura de Alfonso La Torre como figura central en la crítica teatral periodística del Perú.

\section{PALABRAS CLAVE}

El Lunarejo, Juan de Espinosa Medrano, Alfonso La Torre, crítica teatral periodística, oficio crítico.

\section{ABSTRACT}

This essay highlights the figure of Alfonso La Torre as a prominent figure in journalistic reviews in Peruvian theater.

\section{KEY WORDS}

El Lunarejo, Juan de Espinosa Medrano, Alfonso La Torre, theater critic journalistic, critical job.

Para todos es evidente que en este momento hablar de crítica es meterse en camisa de 11 varas. Sería extremadamente ingenuo querer avergonzar a nuestro Ministerio de Cultura señalando que la crítica no está protegida, apoyada o, por lo menos, mencionada en sus planes presentes o futuros de investigación o posibles anhelos de remotas ediciones. Ojalá fuese la crítica la única disciplina que se encuentra en esa situación.

Hasta estas fechas existe un trabajo de investigación denominado Historia general del teatro en el Perú, patrocinado por una universidad capitalina, en una muy loable iniciativa, pero, jay, la crítica!, se hace imprescindible en este pequeño ensayo señalar de entrada una precisión en cuanto a este libro escrito por Aída Balta Campbell. En la parte referida a la crítica brilla una perla tan grande que en un tratado que se arroga el título de «historia general» es imposible pasar por alto. Dice así: «La crítica teatral periodística dejó en los 80 de contar con el arduo trabajo de Alfonso La 
Torre, que abandonó su oficio de crítico por el de autor teatral» (Balta 2001: 278). Yo he realizado una recopilación de las críticas periodísticas de Alfonso La Torre en mi libro Alfonso La Torre. Su aporte a la crítica de teatro peruano, que registra las 66 críticas (Joffré 2012: 100-166) que él publicó del 21 de noviembre de 1981 al 3 de junio de 2000, y que son prueba fehaciente de que la señora Balta afirma algo que no está justificado.

Hecha esta apreciación, vamos a empezar por el principio.

\section{El Lunarejo}

El Lunarejo fue el sobrenombre del escritor apurimeño Juan de Espinosa Medrano, quien, siendo andino, abrazó la cultura europea y se autodenominó «criollo» y adelantado de las letras hispanas. Nació entre 1628 y 1630. Nuestra escritora Clorinda Matto de Turner lo llega a ponderar como una prueba de la superioridad indígena. Fue crítico literario, si vale la expresión, pero crítico al extremo de emplear la figura del papagayo para referirse al intelectual americano, por aquello de estar dotado de habla pero ser simple reflejo de la metrópolis. En este breve intento invocamos al Lunarejo como figura porque no alcanzó a tener teatro que criticar, pero hubiese sido muy interesante que su crítica nos hubiese alcanzado teatralmente hablando.

Muchos años después, en Historia de la República del Perú (1822-1933), de la pluma de nuestro gran historiador Jorge Basadre, encontramos textos como:

El repertorio teatral.- El público que acudía al teatro en Lima estuvo durante mucho tiempo condenado por la moda de las piezas truculentas, melodramáticas, inverosímiles, carentes, casi siempre, de dignidad literaria y escénica. Al calor de ellas, gozaron del favor del público producciones clásicas modernas como algunas tragedias de Voltaire. Hubo también como un renacimiento del gran teatro español a través de producciones de Lope de Vega, Moreto y otros clásicos, a los que fueron agregados los escritores más recientes como Quintana y Moratín, bien o mal representadas.

[...]

A veces fueron llevadas a la escena obras con punzantes alusiones políticas inéditas, como ocurrió con La Monja Alférez, del autor español Juan Pérez de Montalbán, que se representó el 12 de diciembre de 1830 con la asistencia del vicepresidente Antonio de la Fuente y en notoria alusión a la esposa del presidente Agustín Gamarra, doña Francisca Zubiaga. Con este motivo apareció el folleto «Crítica universal contra la representación de La Monja Alférez» (Lima, 1830). También hubo otros casos similares aunque en actitud de jolgorio, como la alegoría en que las tropas de la Ambición optaban por fraternizar 
con las de la Libertad y que tenían relación con el abrazo de Maquinhuayo en 1834 (Basadre 2005: 15).

Es una lástima no tener esa crítica que se denominaba a sí misma como «universal», pero no contamos con ningún dato que nos oriente sobre cómo conseguirla.

Pero sigamos con Basadre:

Felipe Pardo y Aliaga, recién llegado de España en 1828, inició en el diario Mercurio Peruano, con su amigo José Antolín Rudolfo, una serie de crónicas contra el mal gusto de muchas de las obras representadas en el teatro, o su inadecuada presentación, o el risible vestuario de los actores, u otras deficiencias. Comenzó entonces, por rivalidades literarias, generacionales y personales, una larga polémica entre los jóvenes críticos y el clérigo, catedrático y satírico José Joaquín de Larriva, que escribía en El Telégrafo. El debate fue muy vivo, con argumentos contradictorios e ingeniosas letrillas y odas. Lo ha exhumado minuciosamente Raúl Porras Barrenechea en su muy documentado y sabroso estudio titulado «Don Felipe Pardo y Aliaga, satírico limeño» y Guillermo Ugarte Chamorro en una de sus contribuciones tan valiosas sobre la historia del teatro peruano.

La inquina de Larriva contra Pardo y Aliaga resurgió en julio de 1830 cuando este publicó una elegía a la joven señorita Joaquina Moreyra por su fallecimiento. Esta vez las burlas del clérigo tuvieron como tribuna el Mercurio Peruano. Pardo y Aliaga respondió con altura e ingenio en La Miscelánea.

El futuro autor de El Espejo de mi Tierra siguió en sus empeños por la reforma teatral. Hizo representar, de la mejor manera posible, obras de Lope, Moreto, Moratín y Quintana En 1826 había traducido Clitemnestra, tragedia en cinco actos que seguramente no llegó a la escena; y en junio de 1830 dio a conocer otra traducción, ahora del portugués, Doña Inés de Castro. Pero un significado fundamental tuvo su propia comedia en tres actos y en verso Frutos de la educación, presentada el 6 de agosto de 1830 por la compañía de José María Rodríguez, de la que formaban parte, entre otros, Carmen Aguilar y Concepción Rivas. Esta obra señaló el nacimiento del teatro nacional (Basadre 2005: 300).

Este testimonio ya nos ha llevado a un punto muy importante: la aseveración de Basadre de que aquí nace el teatro nacional. Y si es Basadre quien lo dice, los peruanos estamos seguros de que es una apreciación cierta.

Basadre señala también que:

En 1839 tuvo lugar en el proscenio del teatro de Lima un espectáculo inusitado. Fueron quemados unos ejemplares del libro de Flora 
Tristán Peregrinaciones de una paria por considerarse que ofendía y denigraba al Perú. Según el testimonio de Ricardo Palma en su estudio sobre el poeta Esteban de Terralla y Landa, en 1799 habíase efectuado la misma ceremonia con la obra de este autor titulada Lima por dentro y por fuera (Basadre 2005: 305).

Por otro lado, el mismo Basadre, en su Historia de la República del Perú, añade que:

El teatro nacional encontró durante este tiempo, como en anteriores, múltiples obstáculos. Ellos se derivaron de la falta de interés de las empresas casi siempre poco deseosas de invertir dinero en él; la escasa voluntad de muchos actores y actrices, españoles casi todos ellos, conscientes de que tales obras no les iban a servir luego para su repertorio; la frialdad del público; la falta de orientación de la crítica y las dificultades propias de la iniciación artística a base de modelos no siempre recomendables (Basadre 2005, tomo XI: 272) (énfasis en el original).

Me voy a apoyar en un artículo del estudioso y especialista en arte Alfonso Castrillón Vizcarra, quien en uno de sus constantes aportes al estudio de la crítica en general nos dice:

En la Lima de comienzos de siglo, donde los comentarios artísticos eran esporádicos y se encargaban a viajeros o literatos, la figura de Federico Larrañaga representa el prototipo del crítico diletante, versátil, con el aplomo y la osadía propios de su clase. Ingresa a los afanes periodísticos presentado por Clemente Palma, cumpliéndose el requisito de que al mundo prestigioso de la cultura hay que entrar con un padrino de igual prestigio (Castrillón 1980: 81).

Este certero apunte define a aquellos que buscando un lugar para medrar optan por cualquier solución, y teniendo cierta facilidad para llenar unas cuartillas consiguen su primer objetivo y hasta más de lo que se habían imaginado. Claro, este tipo de críticos subsiste y aprovecha poder y gloria. Y en nuestra crítica los ha habido y bastante. Entre nosotros era más frecuente este modelo de crítico.

Con un testimonio personal que viví en mi entrada como actriz al teatro puedo dar fe de que había lo que podríamos llamar una crítica vieja y una crítica nueva. La crítica vieja era tal como la cita Castrillón líneas arriba, y no tiene caso recordar a sus mentores. Fue a partir de las últimas fechas de la década de 1950 que nuestro teatro y nuestra crítica empiezan a recibir nuevos aires de vida.

Se levantaba señera la figura de Sebastián Salazar Bondy, poeta, autor dramático, hombre político y crítico en general de su sociedad y su país, que también ejerció la crítica teatral, esporádicamente: se pueden apreciar 
sus comentarios en los periódicos de la época. En un artículo memorable, titulado «Radiografía actual del teatro peruano», nos da una exacta referencia de la realidad teatral que vivíamos y que examina acápite por acápite: la actuación, la dirección, el repertorio, los aspectos técnicos y el público. Con respecto a la crítica, apunta: «El público hace poco caso de la crítica, pero es dócil a la propaganda sensacionalista (lo que ha llevado a ciertos empresarios a cometer verdaderas afrentas a la dignidad humana)» (Salazar Bondy 1964: 66) ${ }^{1}$. Tal vez la crítica que tenía el carácter de «oficial» en los diarios importantes de la época no era nada apreciable; fue la mejor manera de señalar que realmente no había crítica valedera para el teatro.

Luego de Sebastián hubo otra pluma de un hombre que lo siguió y al que podríamos llamar su discípulo, no en las aulas, pero sí en el teatro, José Miguel Oviedo, mucho más joven que Sebastián, un muchachito serio y con gran sentido de responsabilidad que empezó a asustarnos con su pluma acertada y severa. Su carrera en el Perú se interrumpió porque viajó a estudiar a Estados Unidos y se quedó en ese país. Paralelamente, surgió un periodista que le cambió la cara a la crítica de teatro en el Perú, Alfonso La Torre Rado. Se inició como dibujante de historietas de las tradiciones de Ricardo Palma, en El Comercio Gráfico o El Comercio de la Tarde, y desde allí se inició como crítico. Tuvo que buscar un seudónimo, pues según sus jefes no estaba bien firmar con el mismo nombre los dibujos y las críticas.

Alfonso, que había estudiado Periodismo en la Universidad Católica, se entregó a fondo a la profesión de crítico. Luego de El Comercio Gráfico, continuó en la revista Cultura Peruana, en el diario La Crónica y después en Expreso. A mediados de la década de 1980 sus críticas podían encontrarse en dos diarios: El Comercio y Expreso. Fundador del diario La República (16 de noviembre de 1981), convirtió la página cultural de ese periódico en un verdadero espacio de apoyo, difusión y análisis del arte.

Por la parte que nos corresponde, el apoyo al teatro dado por Alfonso (ALAT) fue decisivo en esas épocas difíciles y hermosas en que surgió un teatro joven, experimental, técnico y que por desgracia no figuraba para nada en los planes oficiales de ninguna índole. Sus reportajes a toda página cuestionando y resaltando el trabajo de los teatristas no se han repetido, si nos referimos a la actitud abierta y consensuada de sus entrevistas. Su oficina en el quinto piso del local de La República, en la calle Camaná 
del centro de Lima, siempre tenía en sus escaleras subiendo y bajando a gente de teatro, sea porque acudía por primera vez a solicitar el apoyo de este periodista que sí atendía a todos, o a los invitados que ya contaban con una larga trayectoria en el teatro. Estuvo 41 años ejerciendo la crítica de teatro, como lo prueba la recopilación de sus críticas, que se han convertido en una historia fidedigna del teatro en los años comprendidos de 1958 a $2000^{2}$.

El hecho de haberme detenido muy especialmente en la figura emblemática de la crítica teatral peruana se debe a que su caso es efectivamente único en nuestra historia de la crítica teatral peruana. No hubo antes un crítico como ALAT y no vislumbro que pueda repetirse un caso como el suyo. Las causas están a la vista: desinterés de los medios que podrían remunerar la labor crítica para que alguna persona pueda sostener su vida trabajando en este rubro; desinterés de las entidades que hacen teatro de afrontar críticas que podrían quitarles los apoyos económicos que son los que hacen posible su continuidad haciendo teatro. Y también los innumerables condicionantes que han hecho variar las formas de comunicarnos públicamente.

Pero sería poco considerado no resaltar que ha habido nombres en el teatro que tomaron la crítica teatral periodística como un serio ejercicio de análisis. Vale recordar, durante el periodo de 1960 a 1990, a Roberto Miró Quesada, a Luis Felipe Ormeño y especialmente a Hugo Salazar del Alcázar. Desafortunadamente, ellos murieron muy jóvenes y no pudieron desarrollar lo que se apuntaba como una interesante promesa.

Entre los que quedamos vivos y todavía tratando de hacer crítica teatral periodística de la mejor manera posible, no quisiera herir susceptibilidades mencionando nombres, porque no he realizado una investigación a carta cabal durante la dura etapa del siglo XXI, y no puedo señalar quién ha quedado en el ejercicio de sus funciones de manera regular y con una remuneración económica debida. A vuelo de página, revisando los periódicos más comunes en nuestra vida diaria, no encuentro ningún nombre que pueda citar.

Sí puedo señalar con certeza el trabajo de un hombre joven y voluntarioso, Sergio Velarde, quien a través de su espacio cibernético llamado El Oficio Crítico despierta el interés de los colectivos teatrales más jóvenes y no precisamente de aquellos que alcanzan los titulares de los medios escritos de mayor influencia. Velarde se da el lujo de hacer un recuento

2 Alfonso La Torre nació en Acomayo, Cusco, el 13 de octubre 1927 y murió en Lima el 3 de diciembre de 2002. Su última crítica de teatro apareció en julio de 2000. Estaba muy debilitado por la enfermedad y no pudo continuar escribiendo. 
anual que tiene un atractivo número de seguidores; naturalmente, la mayoría son jóvenes y amantes del Twitter, el Facebook, los blogs y otras maravillas.

Es verdad que el internet, con sus distintas posibilidades de comunicación y de intercambiar comentarios, noticias, chismes y toda clase de contacto entre la gente que hace teatro y la que asiste a los espectáculos, casi parece estar haciendo innecesaria la crítica teatral como la hemos entendido en décadas pasadas. No afirmo ni niego nada, porque me parece que es prematuro arriesgar una opinión.

Puedo consignar que no me es raro recibir pedidos como: «Dame un palo, de verdad, fuerte», de parte de directores y actores que simplemente quieren conocer una opinión que puedan considerar la menos condicionada posible. Esos pedidos pueden tener su origen en la época en que ejercí la crítica continua durante siete años en El Comercio. De esa forma pudieron calibrar mis aciertos y desaciertos, y tuvieron la oportunidad de sopesar mis opiniones respecto a su trabajo. En la crítica a menudo no es tan importante lo que uno opine o deje de opinar sobre un trabajo teatral, sino cuán justificada está nuestra opinión y cómo la sustentamos.

He tenido la oportunidad de dictar, a pedido del Centro de Estudiantes de Literatura de la Universidad Nacional Mayor de San Marcos, un taller de crítica. Ha surgido de allí un colectivo denominado Crítica Teatral Sanmarquina; gracias a todo lo que conocen los muchachos sobre las redes sociales y otros misterios de internet, han llegado muy bien a la colectividad teatral, sobre todo a la de las ligas menores. Pero cuando uno de ellos me hizo la pregunta del millón: «¿Uno puede ganarse la vida haciendo crítica de teatro?», demoré en contestarle, pese a que durante los siete años que publiqué periódicamente recibí una paga atractiva, lo cual hacía mucho más interesante comentar el teatro. Sopesé ese pasado con lo que puedo apreciar del presente y decidí ser realista en mi respuesta. Tuve muy a mi pesar que responderle: «La verdad, actualmente no se me ocurre dónde».

Allí está el problema: ¿quién paga por la crítica? He ahí la cuestión.

No quiero terminar sin mencionar una hermosa anécdota que muestra la necesidad de expresar un reconocimiento a un buen trabajo, de artista a artista. Esta cita ejemplifica maravillosamente la necesidad de compartir esos sentimientos que una puesta en escena con esa fuerza de lo vivo hacen surgir:

Cuando una actriz o un actor han vivido toda una vida en el escenario, adquieren la extraordinaria capacidad de simplemente «existir» en escena, de cuerpo y alma, con una sencillez, una hondura y una 
sabiduría que solo dan el tiempo, el arte y la experiencia. Ver esta noche en El último fuego, de Ópalo, a Sonia Seminario (sin desmerecer al resto del excelente elenco) ha sido, además de un enorme placer, una celebración de la inmortalidad del teatro, de su conmovedora permanencia, a pesar de su innegable transitoriedad. ¡Bravo por esta gran señora de nuestra escena! Una verdadera lección de teatro y de vida (Ísola 2012).

Este hermoso texto fue dedicado por Alberto Ísola a Sonia Seminario en el Facebook, en diciembre de 2012, espontáneamente, porque era imprescindible, impostergable decirlo.

Así es como yo creo en la crítica. No es sino inevitable hacerla y compartirla. 


\section{REFERENCIAS BIBLIOGRÁFICAS}

BALTA CAMPBELL, Aída (2001). Historia general del teatro en el Perú: Lima: Escuela de Ciencias de la Comunicación Universidad de San Martin de Porres.

BASADRE Jorge (2005). Historia de la República del Perú (1822-1933). Lima: Orbis Ventures S. A.C.

CASTRILLÓN, Alfonso (1980). «La crítica de los diletantes». En Revista de la Universidad Católica, nueva serie nro. 8, pp. 81-93.

ÍSOLA, Alberto (2012). «ßBravo, Sonia!». Comentario de Facebook.

JOFFRÉ, Sara (2012). Alfonso La Torre. Su aporte a la crítica de teatro peruano. Lima: Ornitorrinco Editores.

(1993). Críticos, comentaristas y divulgadores. Lima: Llu-

via Editores.

(2008). Alfonso La Torre: Su aporte a la crítica. Tesis. Universidad Nacional Mayor de San Marcos.

SALAZAR BONDY, Sebastián (1964, 4 de mayo). «Radiografía del teatro peruano». En El Comercio, p. 66. 